\title{
Correction to: Family migration and educational outcomes of migrant children in China: the roles of family investments and school quality
}

\author{
Yunsen $\mathrm{Li}^{1}$ · Junhui Wang ${ }^{2}$. Liang $\mathrm{Luo}^{3}$
}

Published online: 16 February 2021

(c) Education Research Institute, Seoul National University, Seoul, Korea 2021

\section{Correction to: \\ Asia Pacifc Education Review (2020) 21:505-521 \\ https://doi.org/10.1007/s12564-020-09639-9}

In the original publication of the article, the second author affiliation was incorrect. The correct affiliation is given in this correction.

The second author's affiliation is Southwestern University of Finance and Economics, not Southwest.

Publisher's Note Springer Nature remains neutral with regard to jurisdictional claims in published maps and institutional affiliations.

The original article can be found online at https://doi.org/10.1007/ s12564-020-09639-9.

\section{Yunsen Li}

lysen10384@hotmail.com

1 School of Economics, Southwest University of Political Science and Law, Baosheng Road, Yubei District, Chongqing 401120, China

2 Survey and Research Center for China Household Finance, Southwestern University of Finance and Economics, Chengdu 610074, China

3 Collaborative Innovation Center of Assessment Toward Basic Education Quality, Beijing Normal University, Beijing 100875, China 